\title{
Adaptive Droop Control in Energy Storage Systems for Battery Protection Microgrid Applications
}

\author{
Gottipati Madhuri ${ }^{1}$ | Challa Ramaiah ${ }^{2}$ \\ 1,2Department of Electrical Engineering, Vignan Institute of Technology \&amp; Science, Hyderabad, India.
}

To Cite this Article

Gottipati Madhuri and Challa Ramaiah, "Adaptive Droop Control in Energy Storage Systems for Battery Protection Microgrid Applications", International Journal for Modern Trends in Science and Technology, Vol. 06, Issue 05, May 2020, pp.: 122-130; https://doi.org/10.46501/IJMTST060522

\section{Article Info}

Received on 02-April-2020, Revised on 28-April-2020, Accepted on 05-May-2020, Published on 17-May-2020.

\section{ABSTRACT}

This paper proposes an alternative strategy to control the generated power within an isolated ac microgrid with distributed RES. The proposal is to control the terminal voltage of the existing battery banks below or equal its maximum allowable value. This is done by limiting the amount of power that each energy source can generate at each instant. The microgrid frequency is used to characterize the state of charge of the battery bank and quantify to the converters' control systems how much power they need or can generate to maintain under control the internal power balance of the microgrid. The control of the battery banks' terminal voltage implies indirectly the control of their SOC.

KEYWORDS: Battery banks, isolated microgrids, parallel inverters, power control, renewable energy sources (RESs), state of charge (SOC).

Copyright (C) 2014-2020 International Journal for Modern Trends in Science and Technology

DOI: https://doi.org/10.46501/IJMTST060522

\section{INTRODUCTION}

Micro grids are turning into famous of assignment structures because she be able enhance the monitoring quality or reliability on control resources or limit the environmental impact. Micro grid act be able remain classified in twain modes: gridconnected or islanded modes. In general, micro grids are comprised about distributed energy sources (DERs) inclusive of renewable power sources, distributed power tankage systems (ESSs), or partial hundreds [1-3]. However, the usage on renewable energy sources such as breeze then photo voltaic control of micro grids motives monitoring go with the flow versions due in imitation of uncertainties among theirs monitoring outputs. These editions have to remain decreased to forgather power-quality requirements $[4,5]$. This discipline focuses about coping with the issues as are added by means of air power. To compensate because of fluctuations into breeze power, various ESSs have been implemented between micro grids. Short-term ESSs such as much superconducting magnetic energy storage (SMES) structures [6], electrical double-layer capacitors (EDLCs) [7], then flywheel energy storage systems (FESSs) as like nicely as much long-term ESSs certain as like battery strength tankage systems (BESSs) [8-9] are utilized after micro grid control. ESSs perform additionally remain back after limit the rule glide at factor about frequent merger among the grid-connected passion namely properly namely in accordance 
with modify the frequency and voltage about a micro grid within the islanded mode. Among this ESSs, BESSs have been implemented extensively due in accordance with their versatility, excessive strength density, and efficiency. Moreover, their charge has decreased inasmuch as their performance or breath has increased. In practice, BESSs along excessive overall performance such as much clean and quickly strong answer throughout charging then discharging are required for Microgrid control. This overall performance depends on the government overall performance concerning the government electronic converter. Proportional-integral (PI) control is a realistic yet popular control method because BESS monitoring systems. However, PI rule may exhibit unsatisfactory consequences because nonlinear or discontinuous systems [10]. When proper applied, these new, allotted technology gadgets (DG) offer great advantage in conformity with the grid then in imitation of cease users. However, merging DGs between the regular grid is no longer barring empirical challenges. The typical electrical grid was now not designed for power generation sources dispensed close to the ends concerning the T\&D grid. The successful integration over DG government sources requires the single-direction grid structure about the previous transit after a smarter then greater agile bi-directional grid [11]. As DGs proceed after obtain drawing among the electric market, instant wondering yet recent strategies round power generation, parcelling then bad desire proceed after emerge. One over the an increasing number of frequent techniques because merging DGs into the large electric grid is a new twist over an ancient electrical architecture recognized so the Microgrid. Micro grids are areas about the grid so much do function as like section on the larger macro grid then operate autonomously as like a standalone system. The micro grid systems help facilitate the integration of DG belongings within the large electric grid. Further, when true implemented, micro grids execute unbolt a large adjust regarding stacked values for grid operators and electrified customers toughness [12].

\section{System DESCRIPTION}

Fig. 1 illustrates the simplified diagram of a stand-alone Microgrid used to explain the control strategy proposed in this paper. It consists of a GFC, a GSC, and a battery bank. The renewable energy source, in this particular study, is a variable speed wind turbine coupled to a permanent-magnet synchronous generator (PMSG). Depending on the system size, other energy sources and other storage energy systems can be distributed along the Microgrid. The simplicity of this system is useful to show the feasibility of the proposed control strategy without losing generality.

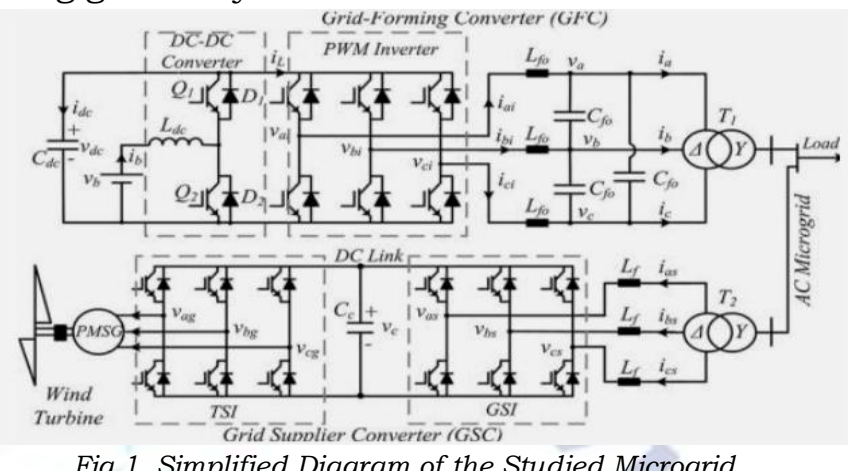

Fig.1. Simplified Diagram of the Studied Microgrid

The GFC is a bidirectional converter formed by a pulse width modulation (PWM) three-phase inverter and a dc-dc converter that works in a buck mode when the battery bank is undercharge or in a boost mode when it is under discharge. The PWM inverter controls the magnitude and frequency of the Microgrid.

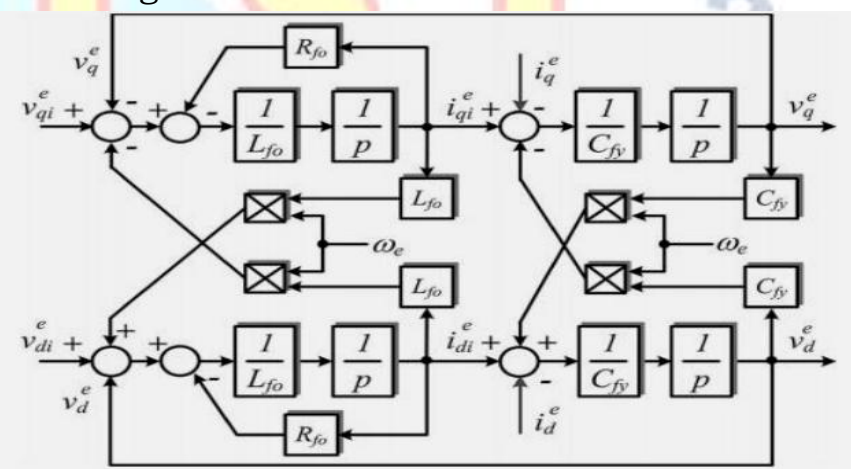

Fig.2. Block Diagram of LC Filter Implemented in a Synchronous Reference Frame

Voltage, while the dc-dc buck or boost converter is used to control the voltage at the dc bus capacitor ( $\mathrm{Cdc}$ ) which is the dc bus voltage as well as the charging and discharging of the battery bank. The GSC is used to control the power generated by the renewable energy source. In this particular example, the converter is formed by a conventional back-to back topology [12]. It has a grid-side PWM inverter (GSI) and a wind turbine-side PWM inverter (TSI). The GSI is used to control the dc-link voltage of the back-to-back topology, and the TSI is used to control the power generated by the wind turbine based on a maximum power point tracker (MPPT) algorithm.

\section{GRID FORMER CONVERTER}

A. Control of the Microgrid Voltage and Frequency 
The Microgrid voltage controller utilizes the conventional design executed on a synchronous dq reference outline, with an inward current circle and an external voltage circle [7]. The recurrence and voltage reference esteems are computed utilizing a hang control methodology as a component of the dynamic and responsive forces, separately, at the lattice previous converter terminals. The dq model of the LC channel in the delta side of transformer T1 (see Fig. 1) is utilized to plan the control circles of the GFC. The square graph of this model is appeared in Fig. 3, where Rfo is the equal arrangement protection of the channel inductor Lfo; we is the Microgrid recurrence in radians every second, the super script's" indicates factors in the dq synchronous reference frame,ied and i.e. q are the dq streams in the delta side of transformerT1; Cfy is the per-stage proportionate capacitance of the LC filterand is equivalent to 3Cfo; and vqe and vde are the dq voltages in the capacitors of the LC channel. The subscript I signifies the yield factors of the GFC PWM inverter. All the square graphs appeared in this paper utilize the administrator $\mathrm{p}=\mathrm{d} / \mathrm{dt}$. Based on the model displayed in Fig. 2, an inward current circle and an external voltage circle were planned, as outlined in Fig. 3.

In this figure, " $\wedge$ " denotes estimated parameters, and GDID1 is the transfer function used to decouple at the sample instants the effect of the disturbances due to the load currents ieqe ied and the cross-coupling due to vq e and vd e. $\mathrm{ZOH}$ means zero-order hold (latch). Fundamentally, the current on the inductance LfO is controlled in order to regulate the voltage on the capacitanceCfO, independently whether the power flux is from the PWMinverter to the Microgrid or vice versa. The voltage reference values for the voltage controllers can be constant, generally equal to the nominal value of the Microgrid voltage, or can be calculated based on a droop control strategy. In this paper, the voltage reference was fixed in $220 \mathrm{~V} / \mathrm{rms}$ line voltage in the delta side of $\mathrm{T} 1$ ).

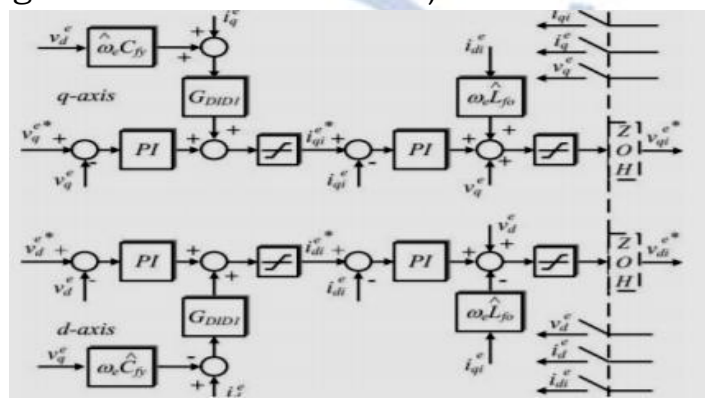

Fig.3. Block Diagram of the Microgrid Voltage Controller

\section{B. Control of the Bidirectional DC-DC Converter}

The dc- dc converter (in GFC) is utilized to control the voltage in the capacitor Cdc. The activity of the controller of thedc- dc converter can be viewed as proportional to interfacing a controlled voltage source, with mean esteem Vct, between the xyterminals of the converter circuit, as appeared in Fig. 4(a) and (b).If the misfortunes in the converter are not viewed as, the voltage onCdc depends just on the contrast between the influence at the battery bank terminals $(\mathrm{Pb})$ and (Pinv) which is the influence at the terminals of the delta side of the seclusion transformer $\mathrm{T} 1$, which is sure when the influence motion is from the inverter to the network and negative unexpectedly. This is appeared in Fig. 4(c).Therefore, the dynamic condition for vdc can be composed as in(1), where wdc is a helper variable characterized by $\mathrm{wdc}=\mathrm{v} 2 \mathrm{dc}$

$\frac{1}{2} C_{\mathrm{dc}} \frac{d v_{\mathrm{dc}}^{2}}{d t}=\frac{1}{2} C_{\mathrm{dc}} \frac{d w_{\mathrm{dc}}}{d t}=P_{b}-P_{\mathrm{inv}}$

From (1) and Fig. 4, the dc bus voltage controller of theGFC can be designed with an inner current loop to control the battery bank current (ib) and an outer voltage loop to control the voltage over the capacitor Cdc, as illustrated in Fig. 6.

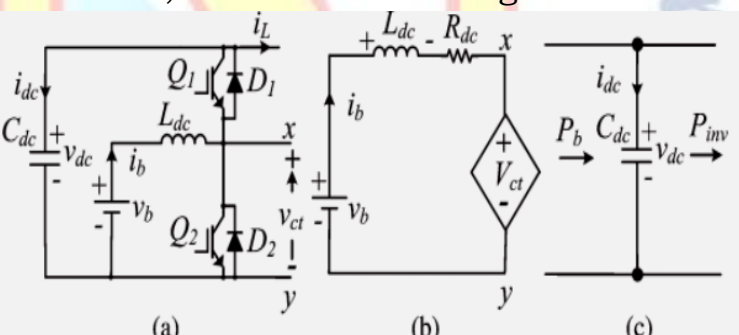

(a)

(b)

(c)

Fig.4. DC-DC Converter Average Model: (a) Original Circuit, (b) Equivalent Average Circuit of Inductor and Battery Bank, and (c) Average Model of the Bus Dc

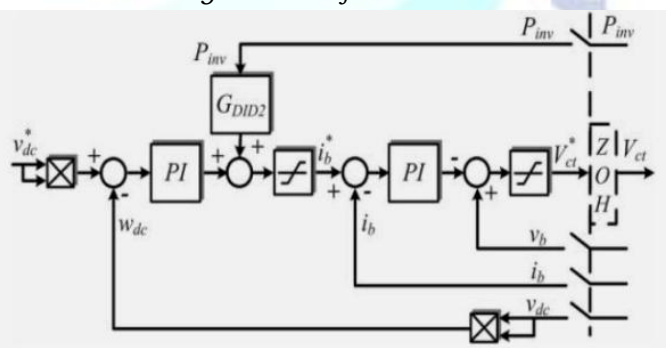

Fig.5. Block Diagram of the Voltage Controller of the Dc- Dc Converter

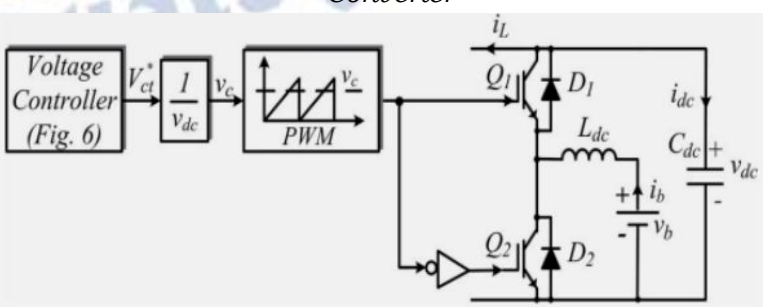

Fig.6. Block Diagram of the Commands for the Switches of the Dc-Dc converter

GDID2 is used to decouple the power disturbance from the output of the inverter over the dc bus 
voltage. The output of the voltage controller (Vct) is the reference value for the PWM block used to generate the control signal forQ1 or Q2 switches, as shown in Fig. 6 [4].In Fig. 6, when Pinv is positive, the battery bank supplies the load, and the $\mathrm{dc}-\mathrm{dc}$ converter functions on the boost mode using the Q2 switch and D1 diode. On the other hand, when Pinv is negative, the dc-dc converter functions on the buck mode using the Q1 switch and $\mathrm{D} 2$ diode.

\section{GRID SUPPlier ConverTer}

A. Control of the Injected Current in the Microgrid and the Voltage at the DC Bus

In this paper, the GSI of the GSC (see Fig. 1) is used to control the dc bus voltage of the back-to-back topology. This controller uses an inner current loop to control the injected current in the microgrid.The current controller is implemented in a dq synchronous reference frame aligned with the Microgrid positive sequence voltage vector. The converter variable synchronization is done by using a synchronous phase-locked loop (PLL) that has a second order resonant filter tuned for the fundamental frequency of the Microgrid.

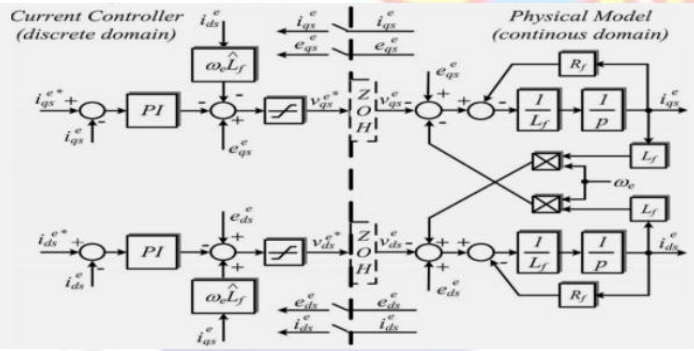

Fig.7. Block Diagram of the Control of the Injected Current in

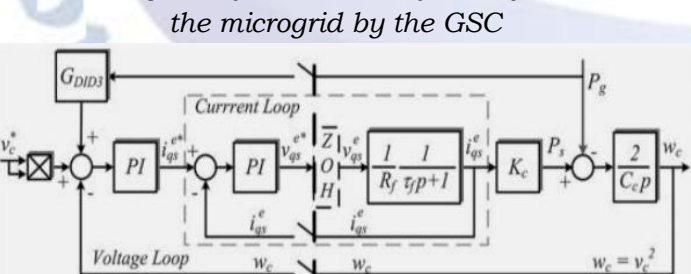

Fig. 8. Block Diagram of the Dc Bus Voltage Controller for the GSC

This PLL additionally has a module to extricate the immediate positive and negative symmetrical segments of the voltage of the Microgrid [13]. The PLL was tuned in view of its little flag investigation demonstrate for a transfer speed of $100 \mathrm{~Hz}$. The piece chart of the present controller together with the channel (Lf) show in a synchronous reference outline is shown in Fig. 8, where $\mathrm{Rf}$ is the proportionate arrangement protection of the inductor Lf, i.e. qs and i.e. ds are the streams in the delta side of transformer T2, and eeqs and eeds are the dqaxis segments of the Microgrid voltage. The embraced current bearing references are the same as those appeared in Fig. 1.If the misfortunes in the GSI and in the inductor Lf are dismissed, the variety of the vitality put away in the capacitor $\mathrm{Cc}$ is equivalent to the distinction between the dynamic influence got from the microgrid (Ps) and the dynamic influence created by the breeze turbine (Pg). Utilizing the tradition of Fig2, this can be communicated as in

$$
\frac{1}{2} C_{c} \frac{d w_{c}}{d t}=P_{s}-P_{g} ; w_{c}=v_{c}^{2}
$$

For a dq synchronous reference frame aligned with themicrogrid voltage vector, it follows that ee $\mathrm{ds}=$ 0 . Therefore, sis equal to (3/2) Esie qs, with Es being the magnitude of the phase voltage, considered constant in this application. By defining Kick equal to $(3 / 2 \mathrm{Es})$, the dynamic equation for the capacitor $\mathrm{Cc}$ is presented in

$$
\frac{d w_{c}}{d t}=\frac{2}{C_{c}}\left(K_{c} i_{q s}^{e}-P_{g}\right)
$$

The block diagram for the dc bus voltage controller is illustrated in Fig. 8. GDID3 is the transfer function used to decouple at the sample instants the effect of the disturbances due to Pg,and tf is the time constant Lf / Rf. The output of the voltage controller is the reference current (i.e. qs $*$ ) for the inner current loop.

\section{Proposed Strategy to Control The GENERATED POWER IN THE MICROGRID}

In remain solitary and circulated sustainable power source frameworks, there is no business or traditional network to assimilate any surplus power produced inside in the Microgrid. In this way, the created control should be controlled when the heap control is not as much as the measure of energy that could be produced by the vitality sources. This is important to keep the vitality adjust in the Microgrid under control and to keep the battery bank voltage underneath or level with its greatest reasonable esteem. This is essential since voltages higher than the gasification voltage can diminish the life expectancy of batteries or even harm them irreversibly [13].In the proposed control technique, the GFC checks the battery bank voltage to know whether it achieved the most extreme permitted charging voltage and, assuming this is the case, change the Microgrid recurrence to educate alternate sources that they should lessen their created control. In view of the Microgrid recurrence, the control frameworks of the power age sources associated with the microgrid choose whether to limit the power produced by each of 
them. This control system can be clarified in view of Fig.9. While the terminal voltage of the battery bank is underneath its most extreme breaking point, the Microgrid recurrence (f) is resolved by the customary hang control technique, portrayed by line $\mathrm{C} 1$ inFig.9, since a physical or virtual inductance is included when the line protection can't be ignored [7]. The recurrence esteem is computed by (8), where $\mathrm{kp}$ is the incline steady of the line C1.On this circumstance, there are no confinements about the measure of energy that can be created, and the current sustainable power sources can work on their greatest power point. Clearly, this is genuine just if the battery bank has been composed with adequate ability to ingest all the power that the sustainable sources can deliver at a given moment

$$
f=f_{0}-k_{p} P_{\text {inv }}
$$

On the other hand, if the maximum voltage of the battery bank is reached, the Microgrid frequency is imposed to be always higher than the value fmax, which is the maximum frequency of operation of the conventional droop control strategy. This is illustrated by the hatched area in Fig.9. Now, the value of the frequency (f) is a variable that changes dynamically

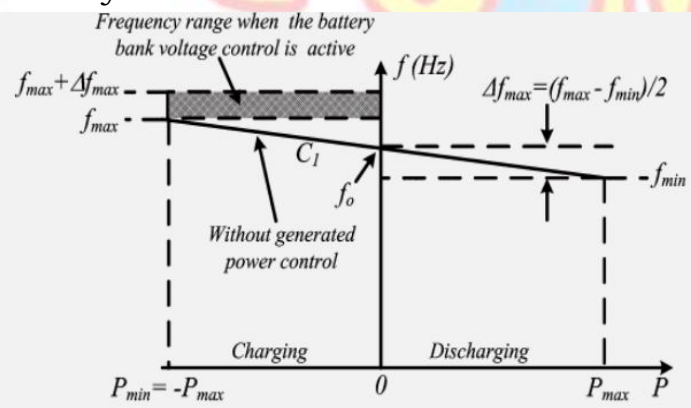

Fig.9. Frequency versus Power in the GFC Based on the Proposed Power Control

With the terminal voltage of the battery bank (vb), the power produced inside in the Microgrid (Pg), and the energy of theGFC (Pinv). This can be communicated by (9). As the estimation of the recurrence relies upon the progression of the battery bank voltage controller, its association with the power (Pinv) does not take after an all around characterized arithmetical condition as, straight line. In this way, Fig. 10 indicates just a delineation that the recurrence can expect any an incentive amongst fmax and fmax $+\delta$ fmax. In this working condition, it is important to confine the measure of energy that can be created by inexhaustible sources; generally, the honesty of the battery bank is in danger. The measure of energy that should be lessened from the most extreme power that each source can deliver at each minute hasa guide connection to the recurrence distinction $\Delta \mathrm{f}=\mathrm{f}-$ fmax. The estimations of fo and $\pm \delta$ fmax embraced in this work are $60 \mathrm{Hzand} \pm 0.60 \mathrm{~Hz}$ with the goal that the recurrence scope of the Microgrid is between $59.4 \mathrm{~Hz}$ (blade) and $61.2 \mathrm{~Hz}$ (fmax + $\Delta$ fmax).

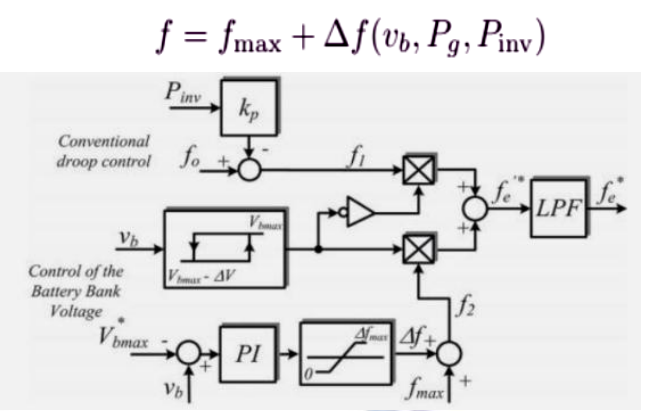

Fig.10. Block Diagram of the Frequency Control at the GFC

A. Implementation of the Proposed Strategy in the GFC

The control of the battery bank voltage, in order to ensure its integrity, was implemented as shown in Fig. 10. While the output of the hysteresis loop is zero, the value of the frequency reference is $\mathrm{fe} *=$ f1. On the other hand, while the output of the hysteresis loop is one, a proportional and integral (PI) controller is used to regulate the terminal voltage of the battery bank equal or below its maximum allowed value (Vbmax).

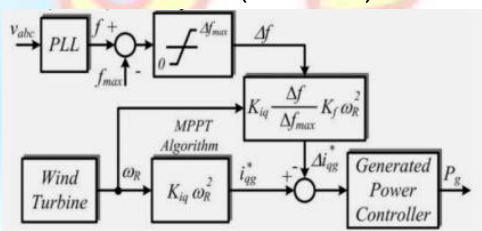

Fig. 11. Block Diagram of the Power Control at the GSC

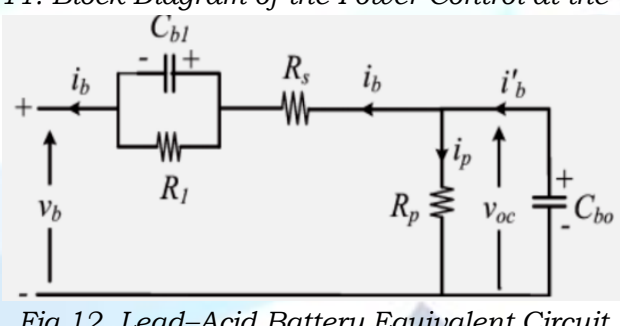

This controller is the increment of frequency $(\Delta \mathrm{f})$ that must beadded to the value fmax to form the new Microgrid frequency reference value ( $\mathrm{fe} *=$ $\mathrm{f} 2=\mathrm{fmax}+\Delta \mathrm{f}$ ). The value of $\Delta \mathrm{f}$ is proportional to the amount of power that must be decremented from the generated power in order to control the battery bank terminal voltage. The low-pass filter with a $1-\mathrm{Hz}$ bandwidth shown in Fig. 12 is used to avoid sudden variations in frequency due the hysteresis loop.

B. Implementation of the Proposed Strategy in the GSC

The lattice recurrence is measured by the GSC and if its esteem is higher than fmax, it implies that 
the voltage of the battery bank is higher than its greatest permitted esteem. For the specific situation where the sustainable power source is a breeze turbine, the GSCpower controller decrements the present reference i* q, initially figured by (7), which is currently ascertained by (10), where Kfis a consistent which serves to coordinate the evaluated energy of the GFCwith the appraised energy of the breeze turbine. The block diagram of this control action is presented in Fig. 12 .

$$
i_{q}^{*}=K_{i q}\left(1-\frac{\Delta f}{\Delta f_{\max }} K_{f}\right) \omega_{R}^{2}
$$

As the reference current is now determined by (6), theoperating points of the wind turbine-generator set follow the dashed curve indicated by Tg in Fig. 8. This implies a reduction in the generator torque, which causes a reduction in power that is produced by the wind turbine keeping regulated the terminal voltage of the battery bank.

\section{Tuning of the Battery Bank Terminal Voltage Controller}

The tuning of the PI controller appeared in Fig. 10 considers the dynamic of the battery bank. One conceivable model for lead-corrosive batteries is appeared in Fig. 12. In this figure, voc is the battery open circuit voltage, $\mathrm{Rs}$ is the proportional arrangement interior protection, $\mathrm{R} 1$ and $\mathrm{Cb} 1$ are utilized to display the over-or under voltage that happens when the battery is charging or releasing, $\mathrm{Rp}$ is the protection due the regular misfortunes, andCbo models the battery ability to capacity vitality. Regularly, the common misfortunes happen gradually, so the impact of $\mathrm{Rp}$ can be slighted with the end goal of this work.

\section{INTRODUCTION TO FUZZY LOGIC CONTROLLER}

From that point forward, a current sound used to be progressed as per stamp the enchanted living arrangements concerning reality, which are extremely intense yet onetime additionally difficult to stand depicted utilizing conventional techniques. Fluffy acknowledge idea has been broadly matured between the administer area incorporating fractional programming in similarity with dcto-dc converter framework. A straightforward diminish rationale government is formed upon through a team concerning rules based in regards to the ethnic information with respect to framework conduct. Matlab/Simulink recreation mannequin is timbered as per lesson the potential direct about dc-to-dc converter then execution over proposed controllers. Besides, chart of fluffy sound judgment senator be capable give perfect both minor solidness flag and sizeable sign potential general execution at indistinguishable time, similar to no longer feasible together with direct manage procedure. Along these lines, supernatural rationale director has been muscular capacity as per enhance the power in regards to dc-to-dc converters. The basic plan over a fluffy rationale controller is demonstrated inside Fig 5 or comprises more than 4 basic angles sure as: a fuzzification interface, who changes over information among reasonable etymological esteems; leverage base, who comprises of a data substandard with the quintessential semantic definitions or the administration regimen set; a basic leadership rationale which, reproducing a human choice process, derive as far as possible employment out of the learning on the point of confinement rules yet phonetic option definitions; a defuzzification interface as yields non fluffy preclude activity of a guessed fluffy govern work [10].

The fuzzy control systems are based on expert knowledge that converts the human linguistic concepts into an automatic control strategy without any complicated mathematical model [10]. Simulation is performed in buck converter to verify the proposed fuzzy logic controllers.

\section{A. Fuzzy Logic Membership Functions}

The dc-dc converter is a nonlinear function of the duty cycle because of the small signal model and its control method was applied to the control of boost converters. Fuzzy controllers do not require an exact mathematical model. Instead, they are designed based on general knowledge of the plant. Fuzzy controllers are designed to adapt to varying operating points. Fuzzy Logic Controller is designed to control the output of boost dc-dc converter using Mamdani style fuzzy inference system. Two input variables, error (e) and change of error (de) are used in this fuzzy logic system. The single output variable $(\mathrm{u})$ is duty cycle of PWM output.

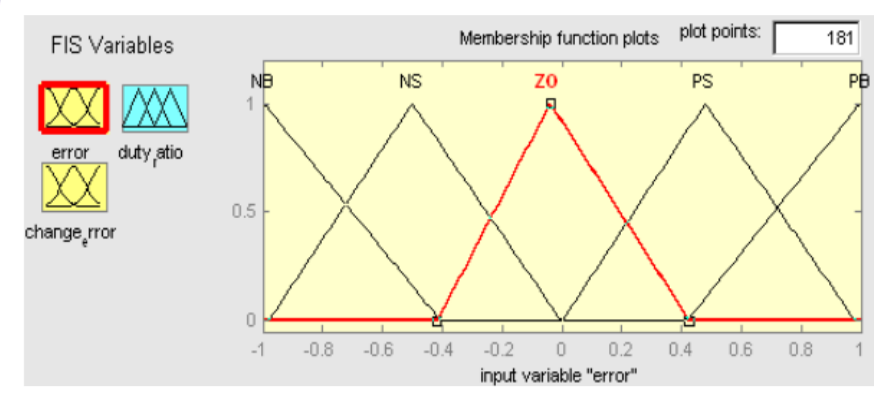


Fig. 15. The Membership Function Plots of Error

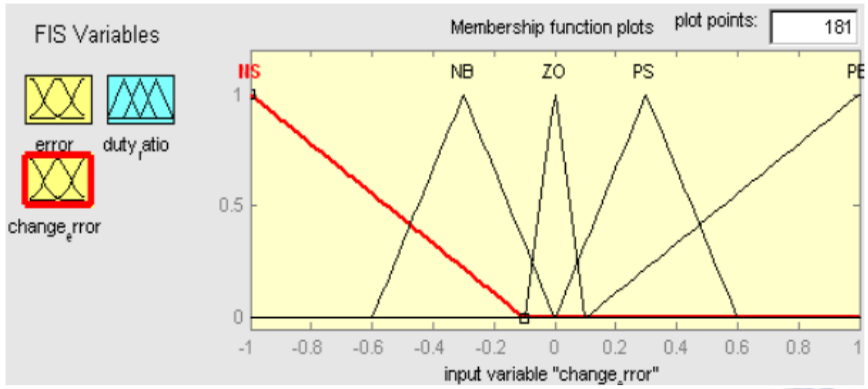

Fig. 16. The Membership Function Plots of Change Error

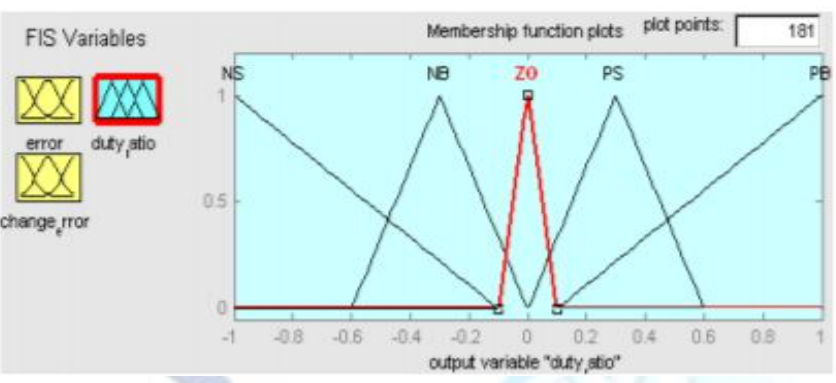

Fig. 17. The Membership Function Plots of Duty Ratio

\section{B. Fuzzy Logic Rules}

The objective of this dissertation is to control the output voltage of the boost converter. The error and change of error of the output voltage will be the inputs of fuzzy logic controller. These 2 inputs are divided into five groups; NB: Negative Big, NS: Negative Small, ZO: Zero Area, PS: Positive small and PB: Positive Big and its parameter [10]. These fuzzy control rules for error and change of error can be referred in the table that is shown in Table I as per below:

TABLE I. Table Rules for Error and Change of Error

\begin{tabular}{|c|l|l|l|l|l|}
\hline (de) (e) & NB & NS & 20 & PS & PB \\
\hline NB & NB & NB & NB & NS & ZO \\
\hline NS & NB & NB & NS & ZO & PS \\
\hline ZO & NB & NS & ZO & PS & PB \\
\hline PS & NS & ZO & PS & PB & PB \\
\hline PB & ZO & PS & PB & PB & PB \\
\hline
\end{tabular}

VII. Matlab/Simulation Results

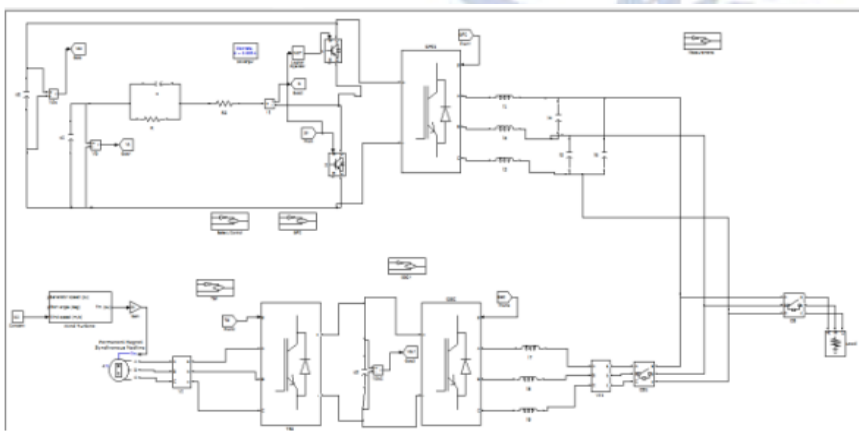

Fig. 18. Matlab/Simulation Circuit of Simplified Diagram of the Studied Microgrid

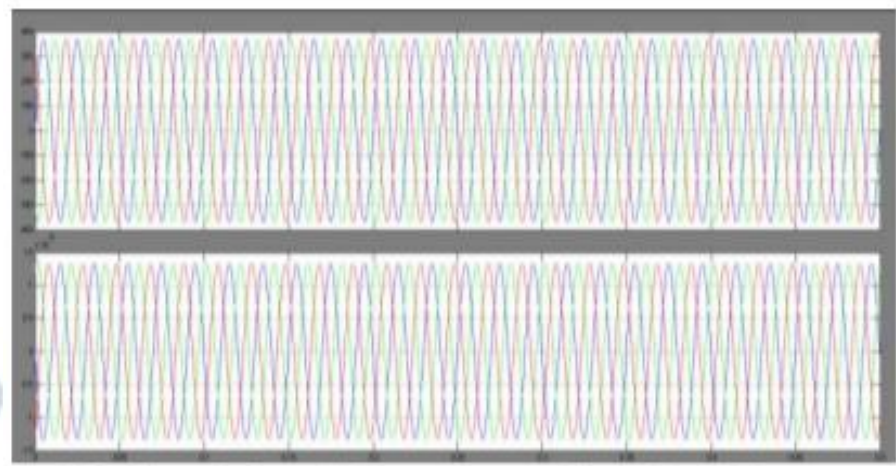

Fig. 19. Simulation Wave Form of Grid Voltage and Current
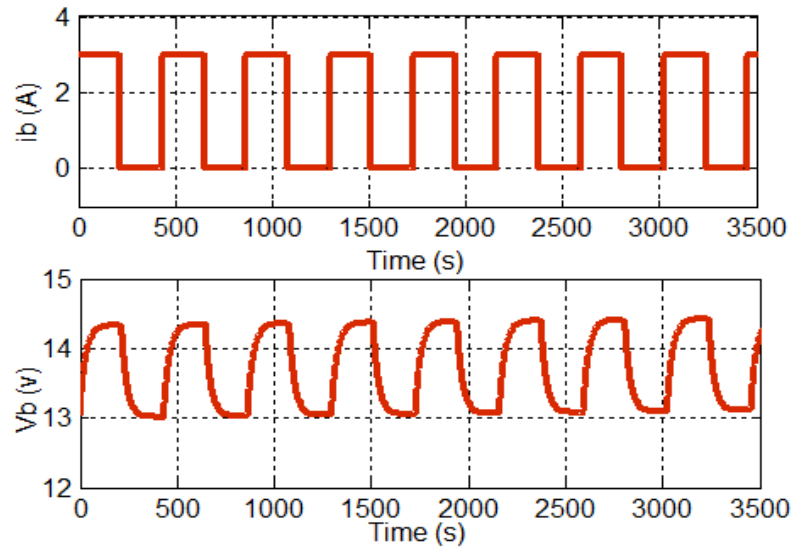

Fig.20. Simulation Wave Form of During the Tests with a 30-Ah 12-V Lead-Acid Battery Current and Voltage

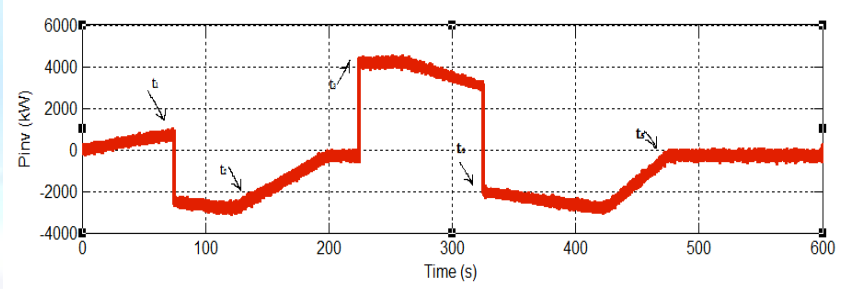

(a)

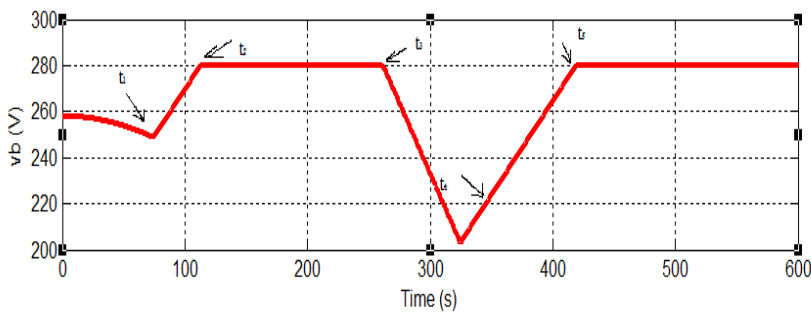

(b)

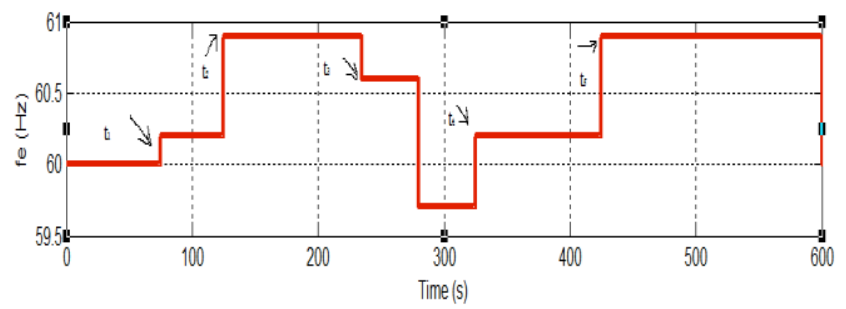

(c) 


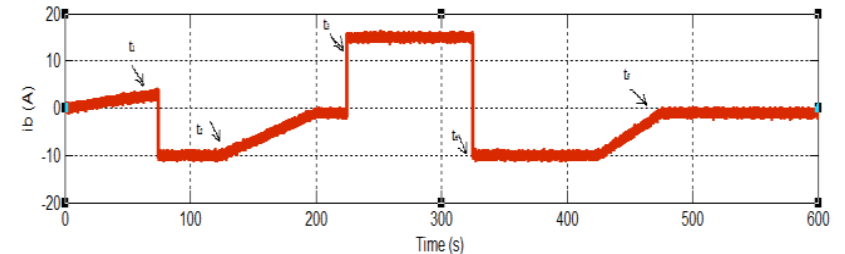

(d)

Fig.21. Simulation Wave Form of Operation with a Constant Wind Speed of $9.2 \mathrm{M} / \mathrm{S}$ : (a) Power at the GFC Terminals, (b) Battery Bank Voltage, (c) Microgrid Frequency, and (d) Battery Current

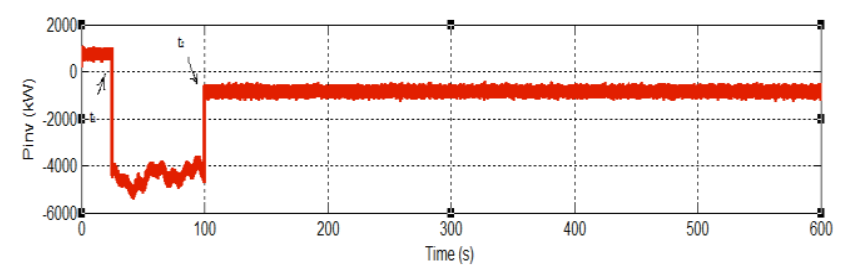

(a)

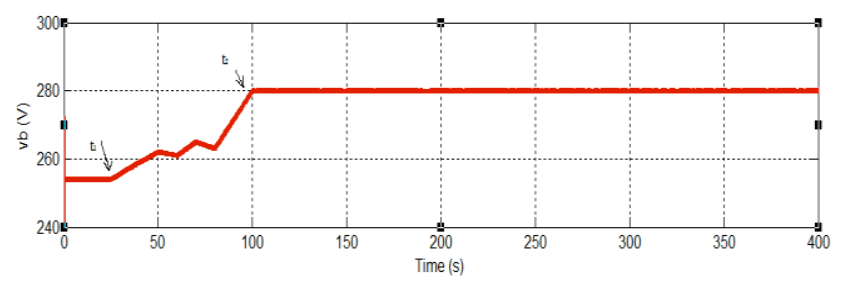

(b)

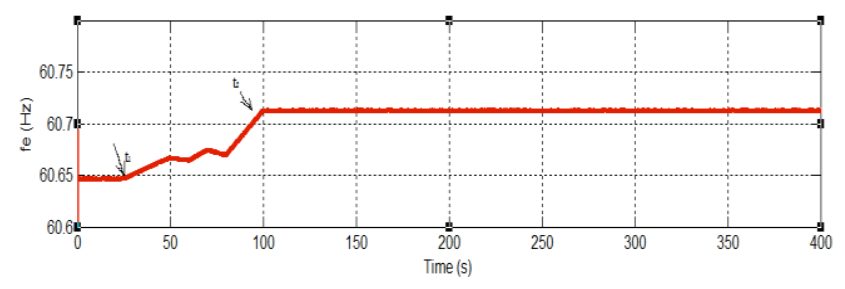

(c)

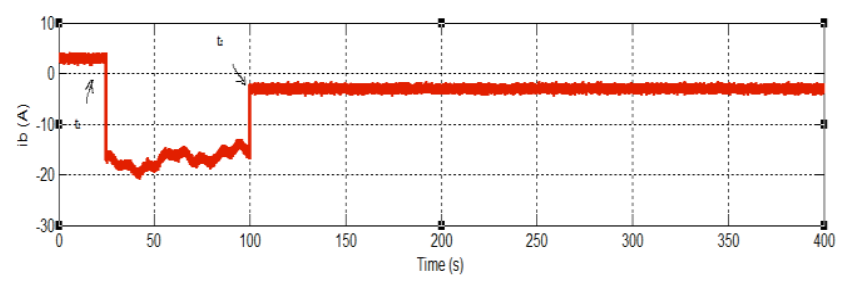

(d)

Fig.22. Simulation Wave Form of Peration with Variable Wind Speed: (a) Power at the GFC Terminals, (b) Battery Bank Voltage, (c) Microgrid Frequency, and (d) Battery Current.

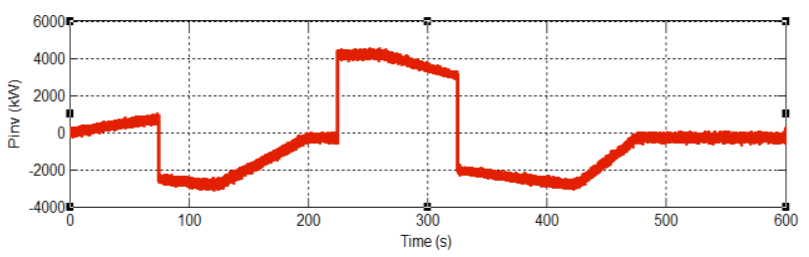

(a)

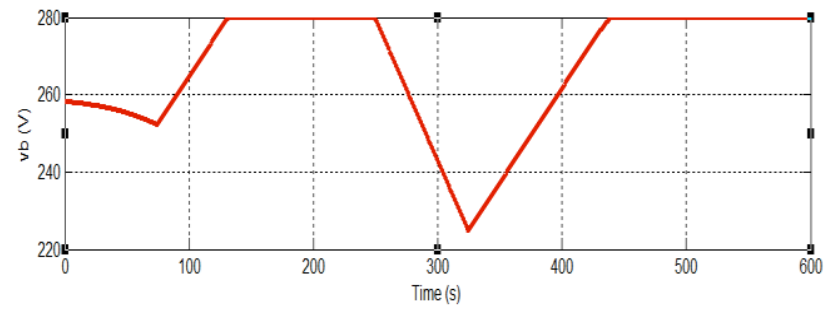

(b)

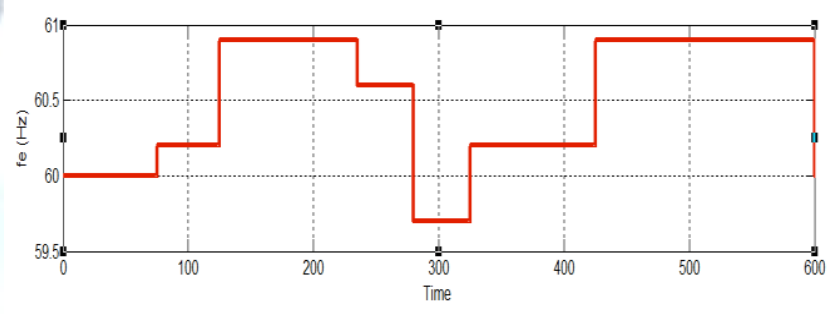

(c)

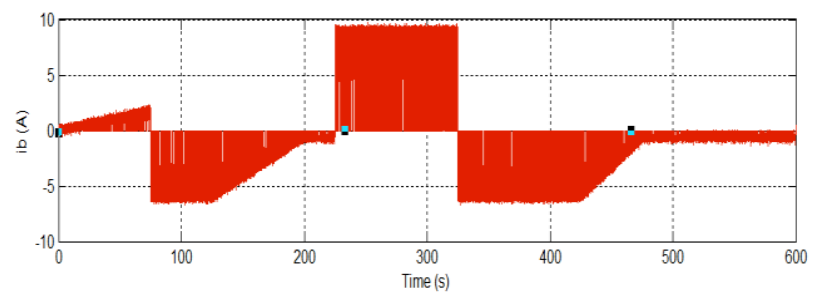

(d)

Fig.23. Simulation Wave Form of Operation with Variable Wind Speed with Fuzzy Controller: (a) Power at the GFC Terminals, (b) Battery Bank Voltage, (c) Microgrid Frequency, and (d) Battery Current

\section{Conclusion}

This paper proposed controller is a procedure to fluffy rationale control the created control so as to monitor the charging voltage battery banks in remain solitary Microgrid with conveyed sustainable power sources. This system does not require wired correspondence between the conveyed sustainable sources nor dump burdens to scatter the excess of created control in the Microgrid. These specialized favorable circumstances make the proposed technique a promising instrument to build the reasonability and unwavering quality of the inexhaustible power age framework introduced in secluded and remote groups. In spite of the fact that a breeze turbine has been utilized to exhibit the legitimacy of the proposed methodology, it is additionally substantial paying little mind to the power source existing in the confined Microgrid. The proposed methodology computes the measure of energy that must be created at each time by each source with a specific end goal to keep the adjust of vitality into 
the Microgrid. At the end of the day, the total of the created, expended, and put away vitality should dependably be zero constantly

\section{REFERENCES}

[1] José G. de Matos, Member, IEEE, Felipe S. F. e Silva, Student Member, IEEE, and Luiz A. de S. Ribeiro, Member, IEEE" Power Control in AC Isolated Micro grids With Renewable Energy Sources and Energy Storage Systems" IEEE Transactions On Industrial Electronics, Vol. 62, No. 6, June 2015.

[2] L. A. de S. Ribeiro, O. R. Saavedra, S. L. de Lima, and J. G. de Matos, "Isolated micro-grid with renewable hybrid generation: The case of Lençóis island," IEEE Trans. Sustain. Energy, vol. 2, no. 1, pp. 1-11, Jan. 2011.

[3] L. A. de S. Ribeiro, O. R. Saavedra, S. L. de Lima, and J. G. de Matos, "Making isolated renewable energy systems more reliable," Renew. Energy, vol. 45, pp. 221-231, Sep. 2012.

[4] J. G. de Matos, L. A. de S. Ribeiro, and E. C. Gomes, "Power control in ac autonomous and isolated micro grids with renewable energy sources and energy storage systems," in Proc. IEEE IECON, 2013, pp. 1827-1832.

[5] N. Mendis, K. M. Muttaqi, S. Pereira, and M. N. Uddin, "A novel control strategy for stand-alone operation of a wind dominated RAPS system," in Proc. IEEE IAS Annu. Meeting, 2011, pp. 1-8.

[6] J. Chen, J. Cheng, C. Gong, and X. Deng, "Energy management and power control for a stand-alone wind energy conversion system," in Proc. IEEE IECON, 2012, pp. 989-994.

[7] M. J. Erickson and R. H. Lasseter, "Integration of battery storage element in a CERTS Microgrid," in Proc. IEEE ECCE, 2010, pp. 2570-2577.

[8] J. Rocabert, J. A. Luna, F. Blaabjerg, and P. Rodrígues, "Control of power converters in ac microgrids," IEEE Trans. Power Electron., vol. 27, no. 11, pp. 4734-4749, Nov. 2012.

[9] C. Jin, P. Wang, J. Xiao, Y. Tang, and F. H. Choo, "Implementation of hierarchical control in dc microgrids," IEEE Trans. Ind. Electron., vol. 61, no. 8, pp. 4032-4042, Feb. 2014.

[10] X. Lu, K. Sun, J. M. Guerrero, J. C. Vasquez, and L. Huang, "State-of charge balance using adaptive droop control for distributed energy storage systems in dc Microgrid applications," IEEE Trans. Ind. Electron., vol. 61, no. 6, pp. 2804-2815, Jun. 2014.

[11] M. A. Abusara, J. M. Guerrero, and S. M. Sharkh, "Lineinteractive UPS for microgrids," IEEE Trans. Ind. Electron., vol. 61, no. 3, pp. 1292-1300, Mar. 2014.

[12] J. M. Guerrero, P. X. Loh, T.-L. Lee, and M. Chandorkar, "Advanced control architectures for intelligent micro gridsPart II: Power quality, energy storage, ac/dc microgrids," IEEE Trans. Ind. Electron., vol. 60, no. 4, pp. 1263-1270, Apr. 2013.

[13] Z. Chen, J. M. Guerrero, and F. Blaabjerg, "A review of the state of art of power electronics for wind turbines," IEEE Trans. Power Electron., vol. 24, no. 8, pp. 1859-1875, Aug. 2009. 